\begin{abstract}
Iranica
Abstracta Iranica Revue bibliographique pour le domaine irano-aryen

Volume 40-41 | 2019

Comptes rendus des publications de 2017-2018
\end{abstract}

\title{
Václav Blažek, Michal Schwarz. Early Indo-Europeans in Central Asia and China. Cultural relations as reflected in language
}

Boris Petipas

\section{(2) OpenEdition Journals}

Édition électronique

URL : http://journals.openedition.org/abstractairanica/50552

DOI : 10.4000/abstractairanica.50552

ISBN : 1961-960X

ISSN : 1961-960X

Éditeur :

CNRS (UMR 7528 Mondes iraniens et indiens), Éditions de l'IFRI

\section{Référence électronique}

Boris Petipas, «Václav Blažek, Michal Schwarz. Early Indo-Europeans in Central Asia and China. Cultural relations as reflected in language », Abstracta Iranica [En ligne], Volume 40-41 | 2019, document 6, mis en ligne le 30 décembre 2019, consulté le 17 avril 2021. URL : http://journals.openedition.org/ abstractairanica/50552 ; DOI : https://doi.org/10.4000/abstractairanica.50552

Ce document a été généré automatiquement le 17 avril 2021

Tous droits réservés 


\title{
Václav Blažek, Michal Schwarz. Early Indo-Europeans in Central Asia and China. Cultural relations as reflected in language
}

\author{
Boris Petipas
}

\section{RÉFÉRENCE}

Václav Blažek, Michal Schwarz. Early Indo-Europeans in Central Asia and China. Cultural relations as reflected in language. Innsbruck: Institut für Sprachen und Literaturen der Universität Innsbruck, 2017, 361p. (Innsbrucker Beiträge zur Kulturwissenschaft, Neue Folge 13)

1 Dans cet ouvrage, V. Blažek et M. Schwarz proposent une étude sur les contacts en Chine et en Asie Centrale entre les populations indo-européennes et leurs voisins, locuteurs de langues non indo-européennes. Cette monographie est alors divisée en quatre parties: la première traite des relation lexicales mutuelles entre les langues tokhariennes et le chinois (p. 21-79), la seconde discute des différentes désignations des noms de métaux en tokharien et en iranien (p. 80-133), la troisième étudie les traces de toponymie et d'hydronymie indo-européenne en Asie Centrale (134-200), enfin la quatrième et dernière partie présente les résultats de plusieurs analyses lexicostatistiques concernant les classifications respectives des langues tokhariennes et iraniennes, tant du point de vue interne qu'externe (p. 201-327). En complément d'ouvrage, à la suite d'une abondante bibliographie (p. 336-355), on retrouve six cartes (chacune de pleine page) couvrant la région qui comprend la mer d'Aral, le lac Balkhash et le bassin du Tarim.

2 Le point notable de cette monographie est l'important volume de données lexicales qu'il contient. Cependant, malgré la quantité de données traitées, le manque 
d'approfondissement de bon nombre de discussions réserve l'usage de l'ouvrage à un lecteur suffisamment initié aux problématiques inhérentes à chacun des domaines concernés par cette étude (tokharologie, iranologie, indologie, linguistique indoeuropéenne, archéologie, etc.) pour remettre correctement en question ses axes de traitements. Plusieurs comptes rendus explicatifs spécialisés discutent précisément de ces différents détails, notamment ceux du sinologue Victor H. Mair (Journal of IndoEuropean Studies 46, 2018, n 3-4, p. 490-499) et des tokharologues Georges-Jean Pinault (Bulletin de la Société de Linguistique de Paris 113/2, 2018, p. 274-286) et Michaël Peyrot (Tocharian and Indo-European Studies 19, 2019, p. 143-146.).

\section{AUTEURS}

\section{BORIS PETIPAS}

EPHE, UMR 8210 Anthropologie et Histoire des Mondes Antiques 